\title{
Difference in Streetscape-consciousness through Evaluation by University Students in Taiwan and Canada
}

\author{
SHU-HUEI LIU \\ Graduate student, University of Tsukuba
}

YASUSHI ASAMI

Professor, University of Tokyo

and

TAKAAKI AMADA

Professor, University of Tsukuba

\begin{abstract}
Questionnaires on streetscape-consciousness of the old (1930s) and the new (1980s) photos of four shopping streets were shown to university students, in Taiwan and Canada, in order to analyze differences in streetscape-consciousness between Taiwanese, East Asians and Canadians, Westerners. According to the results, despite the fact that they look at the same elements in the streetscape, we can argue that differences were found between Taiwanese and Canadian notions of "rustic" and "urban".
\end{abstract}

Key words: Shopping street, Streetscape-consciousness, Evaluation of streetscape, Canada (Western), Taiwan (East Asian)

\section{Introduction}

Because of increasing population and sprawl from the late $19^{\text {th }}$ century, Western cities were facing serious urban renewal or redevelopment problems (Robinson, 1901). Those redevelopment experiences are important reference for East Asian governments to check whether their policy on urban planning will have desired ends. There are so many statements that mention the merits of how 
wonderful it is to rebuild a block into a super-block; or high-rise buildings to fulfill the demands of a high-density population (Hackney, 1990). Yet those theories are leading to cities' death, as Jane Jacobs wrote in her highly acclaimed book named "The death and life of the American cities" in 1961 (Jacobs, 1961). Indeed the problem does not come to a satisfactory solution nowadays. Also there are many different visions that are discussed (Parfect \& Power, 1997).

It is interesting to know whether or not there are any differences between Canadians and Taiwanese concerning the consciousness towards city form. Based on questionnaires taken from university students of Taiwan and Canada in 1997, we will make a comparison between "Canadian" and "Taiwanese," and try to search for a suitable way for supplying a reference to improve Town planning policy of Tainan, which is the oldest historic city in Taiwan. We hope that the results will be taken into account as city planners discuss how to improve the shape, design and appeal of new urban developments. The results do not only apply to Tainan, but are central to the rapid urbanization facing all Asian countries.

\section{Aim of the Research}

From 1997, there were many meetings held on Tainan's Townscape and Town planning. People of Tainan desired to change their city, being the oldest historic town in Taiwan. It needs a persuasive power of change for residences and history. On the other hand, no matter what direction is chosen, to be an international town or a local town, this paper remains useful, because the questionnaire addressed here is thought to be a key to determine what citizens want with their city to look like. One comment is “As a Taiwanese, I don't like the streetscape of Tainan and feel it is an aggregate of dirt, noise and ugly shopping streets. But, I'm not sure what the Westerners think about it." That might be representative of most Taiwanese. Through Canadian students' streetscape-consciousness, this paper will try to reconsider what the historic town of Tainan should do for its future. From comparison of the evaluation of streetscapes between Taiwanese and Canadian university students, this paper would like to analyze any differences in the streetscape-consciousness. To find out the reasons for the differences, this paper considers the views on culture, city surroundings, and life style to try to search for a reasonable explanation behind the differences.

Students in the Department of Urban Planning or related departments of the National Cheng Kung University and those of the University of Toronto answered the questionnaires. Unfortunately, it was not an easy thing for residents to write down their streetscape-consciousness, and therefore we asked university students specializing in related fields to answer them. After gathering those data, this paper will try to analyze the difference of streetscape-consciousness between Canadian (Westerners) and Taiwanese (East Asians). 


\section{Research Area}

Toronto was settled by the British between 1600 (Arthur, 1986) and 1797 (McHugh, 1985). A similar background occurred in Tainan (Tainan City Government, 1992). Even long before 1661, being the origin of the development of Taiwan, Tainan is recognized as the oldest city in Taiwan and developed as a prosperous city by Koxinga, a national hero.

Tainan city is located on the fertile Chia-Nan Plain along the southwest coast of Taiwan (See Fig. 1). It covers an area of $175.65 \mathrm{~km}^{2}$ (about $0.49 \%$ of the whole area of Taiwan) and extends along a coast length of $18.25 \mathrm{~km}$, with population of about 750,000 . With no mountains inside, the geography of Tainan is primarily a flat plain less than 100 meters above sea level. The whole city is triangular in shape (see Fig. 2). The weather is classified as subtropical climate with an average temperature of 23.4 degrees Celsius.

It is impossible for this research to examine all shopping streets in Tainan. Based on the natural and cultural environmental background, four main shopping streets were chosen as a study area. They are Minchuang Road, Minsheng Road, Chungshan Road, and Chungcheng Road (See Fig. 3).

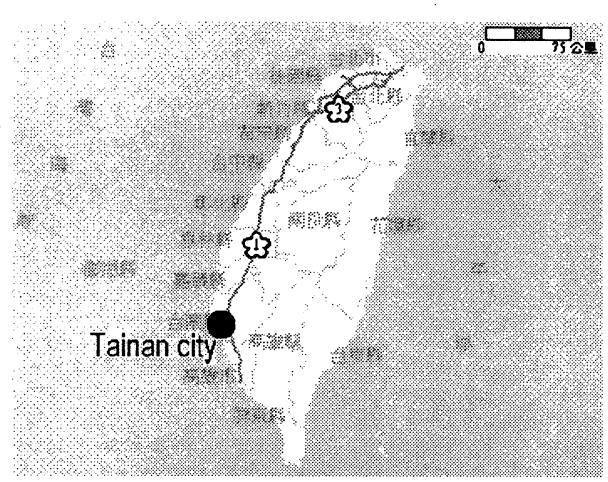

Fig. 1 Location of Tainan city in Taiwan Island

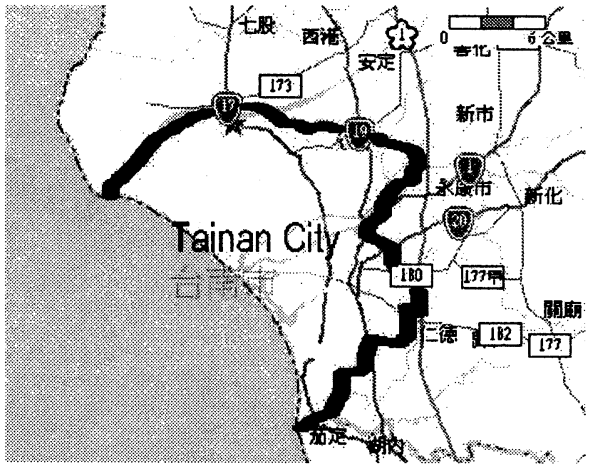

Fig. 2 Shape of Tainan city (Fig. 1; 2 Source: 1998, Reti science) 


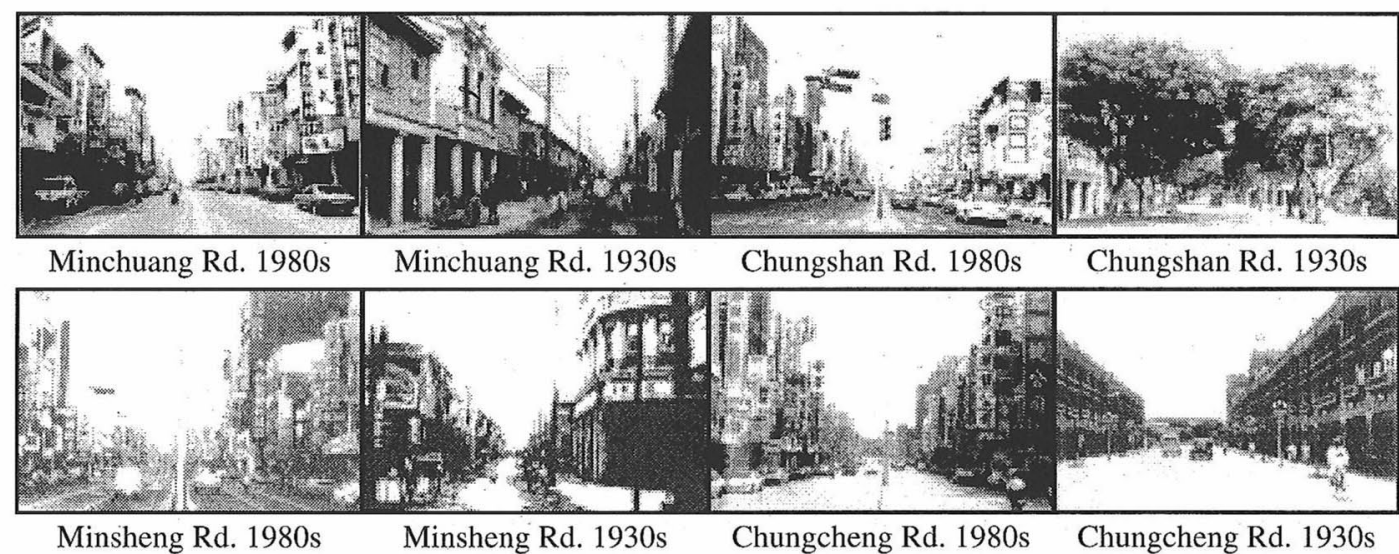

Fig. 3 Photos of four shopping streetscapes of the 1930s and 1980s

(Source: Ju-Shang Chou, Now and Past of FUCHANG, Tainan city government, 1997)

\section{Materials and Methods}

This paper uses questionnaires to try to find out the differences in streetscape-consciousness. The questionnaire was composed of personal face-sheets and questions, which ask about the psychological consciousness about streetscape, through an evaluation of different shopping streets in the 1930s and 1980s. Each pair of the photos is taken at the same location, in the same direction, although after fifty years the scenes have been changed. In this paper we refer to the 1930s as "old" and the 1980s as "new". The purpose is to find out whether the people think that the change is for the good or otherwise. This will help us in knowing whether we should keep the city planning situation as present state or make some changes.

For each photo, the degree of conformity of the 17 adjectives was evaluated by the subjects with "seven scales". Respondents indicated the best scale by circling on the appropriate attributed scale bar. Moreover, for each chosen attribute, they selected the reason or reasons why the scale best fit their idea. There were 45 students of National Cheng Kung University on March 1997 and 47 students of University of Toronto during September-November 1997 who answered the questionnaires. The questionnaire took approximately 2 hours to complete, so after completing the answers very few wrote any extra comments. Statistic Software SPSS (SPSS is a Product of SPSS Inc.) and LOTUS123 (LOTUS123 is a Product of Lotus Development Cooperation) were used for statistical analysis.

To test whether the difference between Canadian and Taiwanese is significant or not, we firstly check the equality of means by t-test. Nationality and 17 pairs of adjectives were chosen as variables. Those independent pairs of adjectives will be picked up in order to testify which nationality tends to have a negative or positive reflection of streetscapes. 
Difference in Streetscape-consciousness through Evaluation by University Students in Taiwan and Canada

Furthermore among those independent pairs of adjectives with 19 reasons, we picked out suitable adjectives and reasons to analyze the differences. To test the difference, chi-square test was used to test whether the null hypothesis that the reasons are the same is accepted or not ${ }^{1}$.

\section{Results and Discussion}

\subsection{General Features}

The questionnaire consisted of two parts. Part one is called a face-sheet. The second consisted of the main detail question for the evaluation. The face-sheet consisted of questions on respondents' personal and related data, by which his/her ideal streetscape could be identified. The results show, Taiwanese and Canadian are similar to each other in responses to "favorite color", "paving material for pedestrians", "control sizes of advertisement boards", and "control the colors of advertisement boards". But, there is clear difference between them on the thought of "ideal home" (See Fig. 4). Most Canadian students are longing for a condominium, while most Taiwanese students prefer Detached Housing. As Fig. 5 shows, there is no Taiwanese students who agree to allow car traffic in a shopping street. Canadian students have fair ideas on car traffic in a shopping street.

Canadians think the car traffic is natural. Comparing the road structure between Taiwan and Canada, it is very clear to understand why Taiwanese students are against the car traffic inside

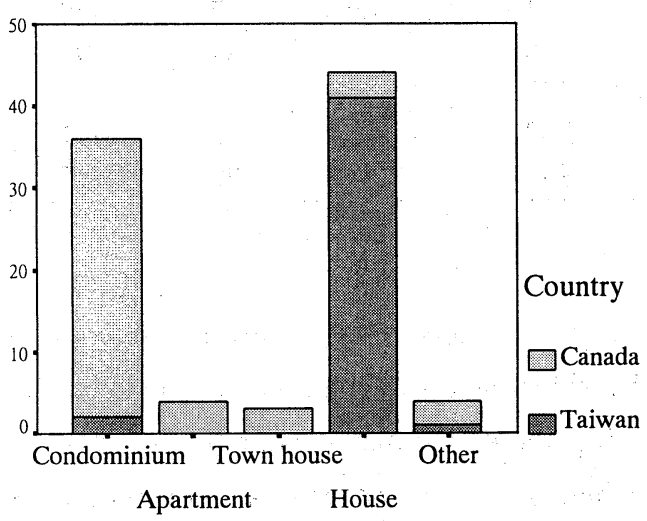

Fig. 4 Proportions choosing options for an "Ideal home"

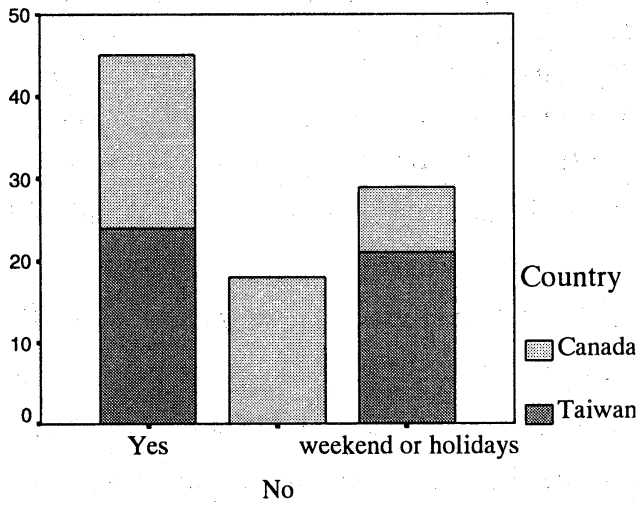

Fig. 5 Proportions who thought the area should be Pedestrian only

1) For example, the difference between Taiwanese (T) and Canadians (C) is tested by the chi-square statistic defined as: $\chi^{2}=\left(N_{T} \times N_{C}\right) /\left(N_{T}+N_{C}\right)\left[\Sigma_{j}\left(P_{T_{j}}-P_{C j}\right)^{2} / Q_{j}\right]$, in which $\mathrm{P}_{i j}=\mathrm{X}_{i j} / \mathrm{N}_{i}, \mathrm{Q}_{j}=\left(\mathrm{X}_{T_{j}}+\mathrm{X}_{C j}\right) /\left(\mathrm{N}_{T}+\mathrm{N}_{C}\right)$, $j=1 \ldots 7$ (element's number in Table 5), $\mathrm{X}_{i j}=$ frequency of $i$ (T or C) who chooses element $j$, and $\mathrm{N}_{i}=$ sum of the frequency of $i$ over $j$. This statistic follows a Chi-square distribution with 6 degrees of freedom. The less the value, the more the difference. See Asami and Segawa (1998) and Takeuchi (1963). 
shopping streets. The most important reason is that most of the Canadian shopping streets have the pedestrian path for people to walk on without a fear to be hit by a car. On the contrary, in Taiwan it is rare to have pedestrian paths and it is extremely difficult to pass through shopping streets due to car traffic. This is also aggravated by illegal parking and stall-keepers ("Yatai" in Japanese; "Tuahuan" in Taiwanese), which occupy the roadside and a great part of the public corridor space.

\subsection{Minchuang Road Case}

Table 1 Comparison of Minchuang Road in the 1930s and 1980s

\begin{tabular}{|c|c|c|c|c|c|c|}
\hline \multirow[b]{2}{*}{ Adjectives } & \multicolumn{3}{|c|}{$1980 \mathrm{~s}$} & \multicolumn{3}{|c|}{$1930 \mathrm{~s}$} \\
\hline & $\mathrm{t}$ & $\mathrm{df}$ & Sig. (2-tailed) & $\mathrm{t}$ & $\mathrm{df}$ & Sig. (2-tailed) \\
\hline Rustic/Urban & 3.504 & 90 & .001 & -9.889 & 90 & .000 \\
\hline Non-Unified/Unified & -6.247 & 89 & .000 & .795 & 90 & .042 \\
\hline Not-charming/Charming & -1.245 & 90 & .147 & .148 & 90 & .029 \\
\hline No-Atmosphere/Atmosphere & -8.095 & 90 & .000 & .522 & 90 & .750 \\
\hline Common/Unique & -2.915 & 89 & .004 & -.385 & 89 & .701 \\
\hline Visually narrow/Visually vast & .129 & 90 & .897 & 2.234 & 90 & .028 \\
\hline Chaotic/Peaceful & 2.984 & 90 & .003 & .776 & 89 & .440 \\
\hline Boring/Interesting & -5.564 & 89 & .000 & -1.503 & 88 & .136 \\
\hline Unfriendly/Friendly & -1.490 & 89 & .140 & 3.716 & 90 & .000 \\
\hline Stressful/Non-stressful & 1.780 & 89 & .079 & .000 & 90 & .077 \\
\hline Inactive/Active & -1.909 & 90 & .059 & -.609 & 89 & .544 \\
\hline Non-humane/Humane & -.898 & 89 & .371 & 3.668 & 87 & .000 \\
\hline Non-historic/Historic & -1.913 & 89 & .059 & .694 & 87 & .490 \\
\hline Ugly/Beautiful & -2.686 & 90 & .009 & 2.168 & 89 & .033 \\
\hline Monotonous/Complicated & -1.037 & 90 & .303 & -2.193 & 90 & .031 \\
\hline Cluttered/Orderly & -.146 & 90 & .885 & 2.850 & 90 & .005 \\
\hline
\end{tabular}

(Significance less than 0.025 marked in bold letters)

Canadian students think that the new (1980s) Minchuang Road is "very urban" and Taiwanese students choose old one as "extremely urban". But why did most Taiwanese students consider the new Minchuang Road as "rustic"? What are they thinking about? Do they mean that they want to change the streetscape of present days? We could ask whether "rustic" means it is more suitable or acceptable.

For Canadian students, scenes of trees along both sides of the street are found not only in housing areas but also in commercial areas. If a scene without trees and complicated artificial look (like advertisement boards with uncontrolled colors and sizes, neon lights or lamps etc.) fills up whole streets, especially the commercial area leads to imagine an urban look. From Table 1 we can understand why the difference occurred between Canadian and Taiwanese students in "urban" and "rustic" images. On the contrary, for Taiwanese students it is a daily experience to see no trees and few 
natural factors along both sides of street. No matter they like it or not, a high proportion of people live in these kinds of area.

According to the results, and if the "urban" means a fine word then it shows that Taiwanese students have a trend to change the style of present days. About 1980s' Minchuang Road the Canadian also think that it is "very unified", "much atmosphere", "unique", "chaotic" and also a "very interesting" street. On the other hand, the Taiwanese people think it looks "very non-unified", "little atmosphere", "very common", "peaceful" and "very boring". From a Western cultural background (obey the law) or life style (enjoy life) or streetscape (orderly); it is not a daily scene or daily feeling. That is one reason why Canadian people may have chosen "very unified", "very atmosphere", "unique", "chaotic" and "very interesting" for the 1980s Minchuang Road. In other words, the Taiwanese may have opposite thoughts compares to Canadian students, related to cultural background (obeying the law less strictly), life style (work hard for life) and a cluttered streetscape. All in all, human being's special antinomy behavior may explain why the two groups appear to have a different reflection.

Concerning the old (1930s) Minchuang Road the Canadian look at the street and choose their answer as "unfriendly", "non-humane" and "cluttered". The Taiwanese say that it is "very friendly", "very humane" and "very orderly". The 1930s Minchuang Road shows old and lowrise buildings along with a quiet street without any trees or colorful advertisement boards. It is not strange that this kind of scene has a negative impression for Canadian people. Maybe it is not surprising then for Taiwanese people to choose it "very friendly", "very humane" and "very orderly".

Taiwanese people have negative image towards the 1980s Minchuang Road and an affirmative image towards the 1930s Minchuang Road. Therefore, we may argue that Taiwanese people feel that it is hard to accept the streetscape of 1980s' Minchuang Road and crave for the 1930s streetstyle.

But, as a tourist strategy, to attract foreign visitors to visit this street, it is necessary to consider how foreigners feel about this street. Is it possible for the government or city planners or even the residents who live and use it to take a good balance in solving this question? Indeed it depends on what kinds of streets are needed for the city. 


\subsection{Minsheng Road Case}

Table 2 Comparison of Minsheng Road in the 1930s and 1980s

\begin{tabular}{|c|c|c|c|c|c|c|}
\hline \multirow[b]{2}{*}{ Adjectives } & \multicolumn{3}{|c|}{$1980 \mathrm{~s}$} & \multicolumn{3}{|c|}{$1930 \mathrm{~s}$} \\
\hline & $\mathrm{t}$ & df & Sig. (2-tailed) & $\mathrm{t}$ & df & Sig. (2-tailed) \\
\hline Rustic/Urban & 8.724 & 90 & .000 & -7.826 & 89 & .000 \\
\hline Non-Unified/Unified & -3.244 & 90 & .002 & 1.278 & 89 & .205 \\
\hline Not-charming/Charming & .595 & 90 & .554 & 1.250 & 89 & .215 \\
\hline No-Atmosphere/Atmosphere & $-\mathbf{5 . 9 5 5}$ & 89 & .000 & -.951 & 88 & .344 \\
\hline Common/Unique & -1.615 & 89 & .110 & -.571 & 88 & .570 \\
\hline Visually narrow/Visually vast & -.641 & 89 & .523 & 2.172 & 87 & .033 \\
\hline Chaotic/Peaceful & 1.018 & 89 & .311 & .853 & 88 & .396 \\
\hline Boring/Interesting & -2.150 & 88 & .034 & -1.187 & 89 & .239 \\
\hline Unfriendly/Friendly & -.499 & 89 & .619 & 1.860 & 89 & .066 \\
\hline Stressful/Non-stressful & 2.625 & 89 & .010 & -.461 & 89 & .646 \\
\hline Inactive/Active & .103 & 89 & .918 & -1.746 & 88 & .084 \\
\hline Non-humane/Humane & .305 & 88 & .761 & .799 & 87 & .427 \\
\hline Non-historic/Historic & -1.526 & 88 & .131 & 1.160 & 88 & .249 \\
\hline Ugly/Beautiful & -.481 & 89 & .631 & 1.951 & 88 & .054 \\
\hline Monotonous/Complicated & -.664 & 89 & .507 & -2.443 & 88 & .017 \\
\hline Cluttered/Orderly & -1.346 & 89 & .182 & 1.439 & 88 & .154 \\
\hline
\end{tabular}

(Significance less than 0.025 marked in bold letters)

Similar to the results for Minchuang Road, the new Minsheng Road makes Canadians feel "very urban" and the old one is "very rustic". Taiwanese have got the opposite reaction; the new is "very rustic" and the old is "very urban". Canadian people feel the new Minsheng Road as "unified"; and the old as "a little complicated". The new Minsheng Road makes Taiwanese people feel "nonunified"; and the old one "a little monotonous".

Besides "rustic and urban", no other pair of adjective shows much difference between the samples in the photographs of Minchuang Road. From the results, it is very difficult to point out what people prefer. Although they have the same reflection like Minchuang Road saying that new Minsheng Road is "very rustic", still we are not very sure which one they prefer. For example: Concerning "charm" for the new Minsheng Road most Canadian chose "neither", and Taiwanese people have mixed viewpoints, with $50 \%$ choosing "not charming" and about $30 \%$ chose "charming". The same mixed results are seen as for "Unfriendly/Friendly". 
Difference in Streetscape-consciousness through Evaluation by University Students in Taiwan and Canada

\subsection{Chungshan Road Case}

Table 3 Comparison of Chungshan Road in the 1930s and 1980s

\begin{tabular}{|c|c|c|c|c|c|c|}
\hline \multirow[b]{2}{*}{ Adjectives } & \multicolumn{3}{|c|}{$1980 \mathrm{~s}$} & \multicolumn{3}{|c|}{$1930 \mathrm{~s}$} \\
\hline & $\mathrm{t}$ & $\overline{\mathrm{df}}$ & Sig. (2-tailed) & $\mathrm{t}$ & df & Sig. (2-tailed) \\
\hline Rustic/Urban & 11.480 & 88 & .000 & -7.318 & 88 & .000 \\
\hline Non-Unified/Unified & -3.279 & 88 & .001 & .000 & 88 & 1.000 \\
\hline Not-charming/Charming & .952 & 86 & .344 & -1.899 & 86 & .061 \\
\hline No-Atmosphere/Atmosphere & -3.340 & 88 & .001 & -2.210 & 88 & .030 \\
\hline Common/Unique & -.534 & 86 & .595 & 1.517 & 86 & .133 \\
\hline Visually narrow/Visually vast & -.398 & 88 & .692 & 2.143 & 86 & .035 \\
\hline Chaotic/Peaceful & 2.251 & 88 & .027 & -2.948 & 87 & .004 \\
\hline Boring/Interesting & -3.509 & 87 & .001 & -1.416 & 86 & .160 \\
\hline Unfriendly/Friendly & -.954 & 88 & .343 & -2.015 & 87 & .047 \\
\hline Stressful/Non-stressful & .283 & 87 & .778 & -3.840 & 87 & .000 \\
\hline Inactive/Active & -1.664 & 87 & .100 & 1.122 & 88 & .265 \\
\hline Non-humane/Humane & -.038 & 87 & .970 & -1.626 & 86 & .108 \\
\hline Non-historic/Historic & -1.619 & 87 & .109 & 2.852 & 87 & .005 \\
\hline Ugly/Beautiful & -.126 & 88 & .900 & .494 & 88 & .623 \\
\hline Monotonous/Complicated & 1.950 & 88 & .054 & $-\mathbf{3 . 5 5 7}$ & 88 & .001 \\
\hline Cluttered/Orderly & -.755 & 88 & .452 & .000 & 88 & 1.000 \\
\hline
\end{tabular}

(Significance less than 0.025 marked in bold letters)

From Table 3, it is very easy to see that the new (1980s) and old (1930s) Chungshan Road has significantly changed its "Rustic/Urban" appearance. This paper finds that more than $80 \%$ of Canadian feel that the new Chungshan Road is "very urban" and the old is "very rustic". More than $85 \%$ of Taiwanese people feel the new Chungshan Road is "very rustic" and the old is "very urban". As shown above, the old Chungshan Road is a little different from other three roads; as there were trees along both side of the road.

The other views of Canadian about the new Chungshan Road are "unified", "much atmosphere" and "interesting". Most of them feel the old as "very peaceful" and "non-stressful"; some of them feel "historic" and "a little complicated". The Taiwanese people feel the new Chungshan Road is "non-unified", "no-atmosphere" and "boring". But, it is not very easy to identify how they feel about the old Chungshan Road, some of them criticize that it is "chaotic"; "stressful", "non-historic" or "complicated" but the others feel "peaceful", "non-stressful", "historic" and "monotonous".

According to the results we can tell that more Taiwanese people like the old Chungshan Road than those who preferred the new road. 


\subsection{Chungcheng Road Case}

Table 4 Comparison of Chungcheng Road in the 1930s and 1980s

\begin{tabular}{|c|c|c|c|c|c|c|}
\hline \multirow[b]{2}{*}{ Adjectives } & \multicolumn{3}{|c|}{$1980 \mathrm{~s}$} & \multicolumn{3}{|c|}{$1930 \mathrm{~s}$} \\
\hline & $\mathrm{t}$ & df & Sig. (2-tailed) & $\mathrm{t}$ & df & Sig. (2-tailed) \\
\hline Rustic/Urban & 9.399 & 88 & .000 & -3.212 & 88 & .002 \\
\hline Non-Unified/Unified & -4.277 & 88 & .000 & 1.614 & 88 & .104 \\
\hline Not-charming/Charming & 2.340 & 86 & .022 & .666 & 86 & .507 \\
\hline No-Atmosphere/Atmosphere & -2.596 & 88 & .011 & -.549 & 88 & .584 \\
\hline Common/Unique & .777 & 86 & .439 & .030 & 87 & .976 \\
\hline Visually narrow/Visually vast & .698 & 88 & .487 & 3.680 & 88 & .000 \\
\hline Chaotic/Peaceful & 3.067 & 88 & .003 & 1.421 & 88 & .159 \\
\hline Boring/Interesting & .734 & 87 & .350 & -1.247 & 87 & .216 \\
\hline Unfriendly/Friendly & 1.379 & 88 & .465 & .187 & 86 & .852 \\
\hline Stressful/Non-stressful & .591 & 87 & .171 & .874 & 87 & .384 \\
\hline Inactive/Active & -.301 & 87 & .556 & -1.827 & 88 & .071 \\
\hline Non-humane/Humane & -.235 & 87 & .764 & .053 & 88 & .958 \\
\hline Non-historic/Historic & -.077 & 87 & .815 & -.740 & 88 & .461 \\
\hline Ugly/Beautiful & 1.211 & 88 & .939 & 1.444 & 88 & .152 \\
\hline Monotonous/Complicated & -.564 & 88 & .229 & -2.974 & 88 & .004 \\
\hline Cluttered/Orderly & .361 & 88 & .574 & .671 & 88 & .504 \\
\hline
\end{tabular}

(Significance less than 0.025 marked in bold letters)

According to the results of comparison (See Table 4), most Canadian feel the image of the new (1980s) Chungcheng Road as "urban" and the old (1930s) as "rustic". Over $80 \%$ of Taiwanese people feel the new Chungcheng Road as "rustic". More than 55\% feel the old Chungcheng Road is an "urban" street.

About the new Chungcheng Road more Canadian people feel "unified", "not-charming", "atmosphere" and "chaotic". More than 70\% of Asian people feel "non-unified", "no-atmosphere" and "chaotic". About "charming" or "not charming" it is very hard to tell. About the old Chungcheng Road most Canadian feel "visually vast" and "complicated" but some of them feel "visually narrow" and "monotonous". Though there is a little difference between Canadian and Taiwanese, still we can point out that most Taiwanese people feel the old Chungcheng Road was "monotonous".

Although we can get an idea that the new Chungcheng Road is not very acceptable, from the results it is difficult to tell whether Taiwanese people like the old Chungcheng Road or not.

\subsection{Difference between Canadian and Taiwanese in their reasons}

Among eight streetscape scenes, this paper chose only intersections and opposite sets of adjectives, e.g., "rustic/urban" to analyze the differences with reasons (See Table 5). 
Difference in Streetscape-consciousness through Evaluation by University Students in Taiwan and Canada

Table 5 The 7 most common reasons among the 19 adjectives

\begin{tabular}{lll}
\hline & \multicolumn{1}{c}{ 1980s } & \multicolumn{1}{c}{ 1930s } \\
\hline A: Building's physical elements & 1. Advertisement board & $\begin{array}{l}\text { 1. Roof and } \\
\text { 2. Window }\end{array}$ \\
& 2. Height, size, material of & 3. Type, height, width of \\
B: Building's property elements & Advertisement board, and & covered sidewalk and \\
& $\begin{array}{l}\text { 3. Height, width, outlook, } \\
\text { material, history of building }\end{array}$ & $\begin{array}{c}\text { 4. Height, width, outlook, } \\
\text { material, history of building }\end{array}$ \\
& 4. Illegal parking and & 5. Electric pole and \\
C: Other features' physical elements & 5. Width of street & 6. Width of street \\
& 6. Material of road surface and & 7. Material of road surface \\
D: Other features' property elements & 7. Brightness, height, art of & \\
& streetlamps & \\
& &
\end{tabular}

We pick up the most common reasons (top 7 of 19 reasons) for analysis. From Table 5 it is easy to understand that there are different words chosen for the two periods. Among those reasons for the new (1980s) scenes, the most obvious factor is "advertisement board" and the old (1930s) the "Height, width, outlook, material, history of building".

Table 6 Differences in the reasons chosen by Canadian and Taiwanese for the 1980s and 1930s streetscapes

\begin{tabular}{lccccccc}
\hline \multirow{2}{*}{ Roads } & \multicolumn{3}{c}{$1980 \mathrm{~s}$} & \multicolumn{3}{c}{$1930 \mathrm{~s}$} \\
\cline { 2 - 4 } \cline { 6 - 8 } & $\chi^{2}$ & $d f$ & $p$ & & $\chi^{2}$ & $d f$ & $p$ \\
Minchuang Road & 14.39 & 6 & $\mathbf{0 . 0 2 6}$ & & 5.255 & 6 & 0.511 \\
Minsheng Road & 9.629 & 6 & 0.141 & & 13.64 & 6 & $\mathbf{0 . 0 3 4}$ \\
Chungshan Road & 2.528 & 6 & 0.865 & & 22.58 & 6 & $\mathbf{0 . 0 0 1}$ \\
Chungcheng Road & 9.943 & 6 & 0.127 & & 15.39 & 6 & $\mathbf{0 . 0 1 7}$ \\
\hline
\end{tabular}

Table 6 shows that the vision of Minchuang Road is different between Canadian and Taiwanese for the new (1980s) photograph. There are different visions between Canadian and Taiwanese in the old (1930s) Minsheng Road, Chungshan Road and Chungcheng Road photographs, but not for Minchuang Road. In other words, for the new Minchuang Road and old Minsheng, Chungshan, Chungcheng Roads, Canadian and Taiwanese people look at the different elements of streetscape and have different judgments. On the contrary, for the 1980s Minsheng, Chungshan, Chungcheng Roads and the 1930s Minchuang Road, Canadian and Taiwanese people look at the same elements of the streetscape and have different judgments.

The Canadian people look at the new Minchuang Road as "urban" with different elements as Taiwanese people feel "rustic". The Canadian people look at the new Minsheng, Chungshan, and Chungcheng Roads as "urban" with the same elements that Taiwanese people feel "rustic". Similarly there is a difference in the old Minchuang Road, which is seen as "rustic" with the same 
elements as Taiwan people feel "urban". By looking at different elements, most Canadian people consider the Minsheng, Chungshan, and Chungcheng Roads of the 1930s as "rustic" while most Taiwanese people feel it to be "urban". No matter what makes them have a different opinion, they watch the same or different elements, and the value judgment may come from culture, life style and city surroundings. Just as is written above there are many ordinary scenes like trees planted along both roadsides; pedestrian ways along shopping streets, which exist in Canadian people but are not ordinary for Taiwanese people.

Sometimes Western people's non-ordinary scene is just East Asian peoples' very ordinary and they just live inside that scene. Some people say Western people can more easily relax themselves and enjoy life; while East Asian people are always working to earn more money and live a more nervous life style (Kulin, 1995).

\section{Conclusions}

Just like Robertson Davies said before "I always think of Toronto as a big fat rich girl who has lots of money, but no idea of how to make herself beautiful" (Relph, 1997). Or we still can read phrases like "Yet Torontonians can take some satisfaction from the fact that Professor Arthur is likely to be wrong in predicting for the turn of the next century that, "in the march of progress, every vestige of our nineteenth-century "heritage" will have disappeared, and only University College, Osgoode Hall, the old City Hall, St Lawrence Hall, and a few churches will remain.' ...." (Arthur, 1986). Sometimes we have got to admit that in democratic countries, it is just like a common sense that any kind of policy even a wonderful proposal, will possibly meet an opponent. So as we had already known Toronto was chosen to be the fourth best city in the world to live by a Geneva-based social survey company in 1995 (Relph, 1997).

According to the results of Table 7, we get an idea of how Canadian university students look at Tainan streetscapes, though they might not have visited Tainan before, and how the Taiwanese uni-

Table 7 Image of the differences between Canadian and Taiwanese on streetscapes

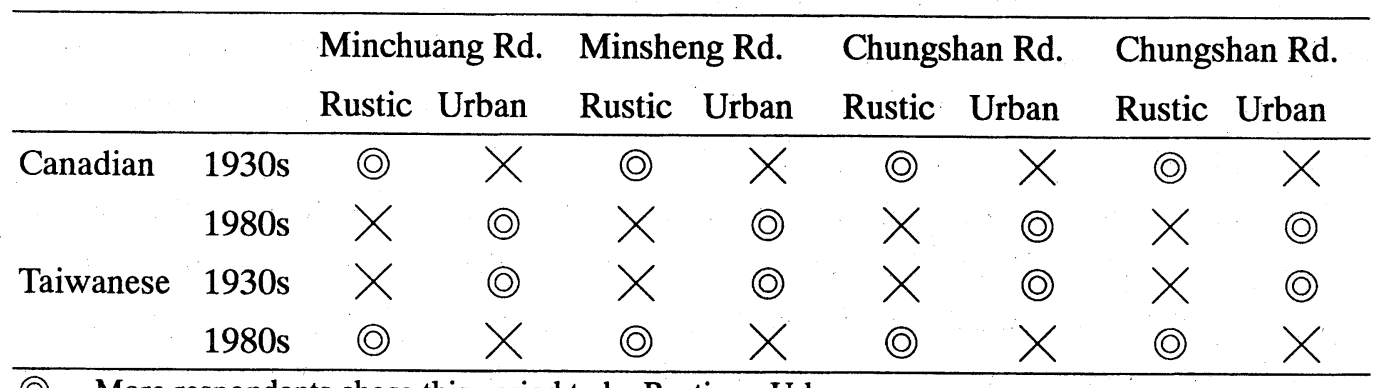

() = More respondents chose this period to be Rustic or Urban. 


\section{Difference in Streetscape-consciousness through Evaluation by University Students in Taiwan and Canada}

versity students look at their old historical shopping streetscapes. From Taiwanese people's viewpoint we know that they wish to change their streetscapes. Referring to Western people's opinion we can trace how they build or rebuild their streets (Arthur, 1986). It depends on what they want their streets to be. The same applies to Tainan; the most important thing is what Tainan's people want their streets to be.

Whether or not they look at the same or different elements of streetscapes, the Canadian and the Taiwanese university students have obviously different thoughts on the definition of "rustic" and "urban" for the eight situations (the 1980s and 1930s) of the four streets used in this research. More than $80 \%$ of Canadian thinks the 1980s streetscape of Tainan is "very urban" and the 1930 s is very "rustic". On the contrary, the Taiwanese people feel the 1980s is "rustic" and the 1930s is "urban".

According to the results, we can argue that most Western people may not have negative thoughts about the East Asian streetscape of present days. Although local (Tainan) residents have a strong desire to rebuild their streets, to make a reasonable balance between Western and East Asian thoughts is very important.

If the shopping street is to be rebuilt for local use, then we can supply a clear opinion to the committee of streets. On the other way, in order to attract more tourists into the city, the opinions of the tourist should be given utmost priority and should be considered. Between "ideal" and "practica1", reaching a good balance considering these conditions is still a tribulation to the government or city planners, and to the residents who live there.

Due to the limited study on the cultural background for the Taiwanese and the Canadian, the essential reason for the difference on the view of "rustic" and "urban" landscape remained unexplained fully. To tackle this issue, we will need to conduct questionnaire survey for those who have different cultural background and living experience. For example, to distinguish the difference between the residents' view and tourists' view, we may need to ask the similar questionnaire for Taiwanese living in Tainan and Taiwanese living outside of Tainan. To distinguish the difference between Eastern culture and Western culture, we may need to include information on the cultural circumstances in which those who are to answer the questionnaire have grown up. Such analysis may clarify the essential source of the different view, which is a very interesting direction of research suggested by the present study.

\section{Acknowledgement}

The authors are grateful to Professor Y. Higano, Dr. D. Macer, Dr. C. A. McLeod, Professor Waterhouse, Professor D. A. McQuillan, Professor R. Jaakson, Professor R. M. Wright, Professor L. Irvine, Professor E. Relpf, and Professor L. S. Bourne; Miss P. Hou, Professor C. Huang; Professor S. Kong and to the reviewers for the journal, for invaluable advice on the paper and helping to finish questionnaires. Many thanks to those students of National Cheng-Kung University and the University of Toronto who answered these questionnaires in 1997. 


\section{References}

Arthur, E. (revised by Stephen A. Otto), 1986, Toronto: No mean city, University of Toronto Press, Toronto. Asami, Y., and S. Segawa, 1998, Low Fertility phenomena and housing conditions, Quarterly Journal of Housing and Land economics, vol. 29, 26-33. (in Japanese)

Hackney, R., 1990, The good, the bad \& the ugly: cities in crisis, Frederick Muller, London.

Jacobs, J., 1961, The death and life of the American cities, Random House, New York.

Kulin, 1995, The ugly Taiwanese, Taiya Press, Taipei. (in Chinese)

Parfect, M., and G. Power, 1997, Planning for urban quality: urban design in town and cities, Routledge, New York.

Relph, E., 1987, The modern urban landscape, The Johns Hopkins University Press, New York.

Relph, E., 1997, The Toronto guide, University of Toronto Press, Toronto.

Robinson, C. M., 1901, The improvement of town and cities, The Knickerbocker press, New York.

Tainan City Government, 1992, Introduction to Tainan, Tainan City Government, Tainan. (in Chinese)

Takeuchi, K., 1963, Mathematical statistics, Toyo-keizai-shimposha, Tokyo. (in Japanese) 